Article

\title{
Political Memes and Fake News Discourses on Instagram
}

\author{
Ahmed Al-Rawi \\ School of Communication, Simon Fraser University, Burnaby, V5A 1S6, Canada; E-Mail: aalrawi@sfu.ca
}

Submitted: 31 July 2020 | Accepted: 22 August 2020 | Published: 3 March 2021

\begin{abstract}
Political memes have been previously studied in different contexts, but this study fills a gap in literature by employing a mixed method to provide insight into the discourses of fake news on Instagram. The author collected more than 550,000 Instagram posts sent by over 198,000 unique users from 24 February 2012 to 21 December 2018, using the hashtag \#fakenews as a search term. The study uses topic modelling to identify the most recurrent topics that are dominant on the platform, while the most active users are identified to understand the nature of the online communities that discuss fake news. In addition, the study offers an analysis of visual metadata that accompanies Instagram images. The findings indicate that Instagram has become a weaponized toxic platform, and the largest community of active users are supporters of the US President Donald Trump and the Republican Party, mostly trolling liberal mainstream media especially CNN, while often aligning themselves with the far-right. On the other hand, a much smaller online community attempts to troll Trump and the Republicans. Theoretically, the study relies on political memes literature and argues that Instagram has become weaponized through an ongoing 'Meme War,' for many members in the two main online communities troll and attack each other to exert power on the platform.
\end{abstract}

\section{Keywords}

fake news; Instagram; polarization; political memes; social media

\section{Issue}

This article is part of the issue "Disinformation and Democracy: Media Strategies and Audience Attitudes" edited by Pere Masip (University Ramon Llull, Spain), Bella Palomo (University of Málaga, Spain) and Guillermo López (University of Valencia, Spain).

(C) 2021 by the author; licensee Cogitatio (Lisbon, Portugal). This article is licensed under a Creative Commons Attribution 4.0 International License (CC BY).

\section{Introduction}

This study started as an exploratory one to investigate the hashtag \#fakenews on Instagram, but the researcher was surprised to find the extent of political polarization, racism, and hate on this platform around this issue which prompted him to pursue this project in more detail since it was possible to collect data referencing to a hashtag on Instagram. The research empirically examines fake news discourses on Instagram by focusing on memes and offers a unique analysis of visual metadata, a feature that has not been examined before in relation to the quantitative analysis of visual discourses on Instagram. From a theoretical point of view, the article attempts to expand on the political memes literature by arguing that Instagram has become a weaponized platform despite its reputation in popular culture as a cool space for young people to post their selfies, food, and travel pictures.
Here, political memes are designed and disseminated to troll opponents in different online communities in what appears to be a Meme War founded on ideological differences and beliefs (Al-Rawi, 2020). The continuation and enhancement of this Meme War is facilitated by the platform's positive apolitical reputation and structure that is built on sharing funny memes, yet the reality is different and far more toxic than is thought, as will be shown here.

Instagram has been largely understudied due to the difficulty of obtaining large datasets from this platform (Highfield \& Leaver, 2015). Unlike the case of other social media outlets like Twitter and Facebook, the other unique aspect of this research study is that it investigates fake news discourses on Instagram as previous studies analyzed fake news on other social media platforms and mainstream media, as well as the use of bots (Al-Rawi, 2019a; Al-Rawi, Groshek, \& Zhang, 2019; Lazer et al., 2018; Vosoughi, Roy, \& Aral, 2018). 


\section{Literature Review}

This article focuses on political memes and how they are used in relation to fake news discourses on social media partly following the recommendation made by Leskovec, Backstrom, and Kleinberg (2009) on the importance of studying political memes and their diffusion. In its basic form, a meme is part of today's participatory and mainstream culture (Jenkins, 2006) and is generally defined as an "image, video, piece of text, etc., typically humorous in nature, that is copied and spread rapidly by internet users, often with slight variations" (Meme, 2020). A more detailed definition is presented here:

Internet memes are digital texts-verbal, visual, or audial-that share common attributes and undergo variations by multiple users. They are created with awareness of one another, and they require prior acquaintance for proper production and consumption, as the repetitive (or memetic) element of the text often incorporates coded cultural information essential for proper interpretation....This practice facilitates, on the one hand, the expression of originality and creativity, and, on the other, a sense of belonging to a cultural collective. In this sense, the memetic practice meets both the demand for individualism and the yearning to belong characteristic of participatory culture. (Gal, 2018, pp. 529-530)

The term was first introduced by Richard Dawkins, a biologist, who mentioned that memes are transmitted units of culture which are similar to genes because they are disseminated either by copying or imitation (Dawkins, 1976). Indeed, memes have become very popular today because of social media. Similar to viral content, many memes are widely shared on Social Networking Sites (SNS), and they often replicate and reappear in different formats, shapes, and contexts (Tay, 2014, p. 48). Hence, memes are understood to be "socially constructed public discourses in which different memetic variants represent diverse voices and perspectives" (Shifman, 2014, p. 7).

One of the important features of memes is their importance in bringing digital communities together (Nissenbaum \& Shifman, 2017, p. 485). Here, Limor Shifman stresses that memes operate on microlevel due to their associated and engaged small online communities, but they are also vital at the macrolevel because they often shape public discourses and enhance collective identities (Shifman, 2012). Indeed, they “play an integral part in some of the defining events of the twentyfirst century" (Shifman, 2014, p. 6). In other words, many digital communities share and disseminate relevant memes that reflect their ideologies through which they practice gatekeeping activities (Burgess, 2008; Miltner, 2014). In this regard, memes are understood to be cultural productions produced and/or disseminated by activists, sometimes called "warriors," in their efforts to oppose and possibly change the status quo (Lasn, 2012, p. 147); even the dissemination of these memes is considered "a product of societal and communal coordination" (Nissenbaum \& Shifman, 2017, p. 485). Shifman (2014) mentions here that memes have three functions: as forms of persuasion or political advocacy, as grassroots action, and as expression and public discussion (p. 122). Due to these functions, memes carry power which is why many online users are "fighting for the hegemony of memes" in what is known as "memes warfare" (Häkkinen \& Leppänen, 2014, p. 7, 19). In this regard, Nissenbaum and Shifman (2017) emphasize that memes have three formulations as capital: subcultural knowledge, unstable equilibriums, and discursive weapons, and even the word discursive indicates that there is some kind of "repetition" or "thematic matter from within an established meme" (Wiggins \& Bowers, 2015, p. 7). In addition, Seiffert-Brockmann, Diehl, and Dobusch (2018) indicate that memes contain three types of communication logic: wasteful play online, social media political expression, and cultural evolution. Finally, Shifman (2014) views memes as playing a role in the "new landscape of Web-based political participation, both in grassroots and top-down campaigns" (p. 122). In this article, we focus on the discursive weapons and features of political expression that are directly linked to fake news discourses and main functions of memes.

Due to the affordances of social media, political memes often have global outreach as they are used in different political contexts and regions in relation to resistance, activism, and "democratic subversion" (Shifman, 2014 , p. 123). They often have many implied meanings that carry ideological undertones. In China, for instance, memes are used to express political views about social norms (Yang, 2014), while memes in Russia are often employed as a networked political action and protest against Vladimir Putin (Lonkila, 2017). In some cases, photoshopped images presented in the form of memes are used to protest perceived injustice regarding police acts (Bayerl \& Stoynov, 2016). In the US, some ironic memes were used to make comparisons between Barack Obama and Martin Luther King such as the case 'I Have a Drone' meme challenge (Howley, 2016). In other words, memes can express "reactions to and protests against political events and figureheads" (Häkkinen \& Leppänen, 2014, p. 7). In a Twitter study on the 2014 Brazilian presidential election, a total of 599 memes were analyzed following Shifman's conceptualization, categorizing them as follows: persuasive, grassroots action, and public discussion (Chagas, Freire, Rios, \& Magalhães, 2019). Another study examined the use of memes on Twitter during the 2015 State of the Nation Debate in Spain, and the content analysis shows significant differences in the use of memes by a variety of Spanish political parties (Martínez-Rolán \& Piñeiro-Otero, 2016). Similarly, during the 2008 US election, video memes like 'Obama Girl,' 'Wassup,' and 'Yes We Can' became very popular attracting the attention of millions of users (Shifman, 2014 , p. 124), while other memes were used to troll 
Barack Obama during the 2012 presidential campaign, presenting him as unpatriotic such as using the 'crotch salute,' 'left-hand salute,' and 'Veterans Day non-salute' memes (Burroughs, 2013). Finally, and as will be mentioned below, memes were aggressively used during the 2016 US election often targeting Hillary Clinton and Donald Trump (Denisova, 2019). In brief, memes are viewed as creative and often funny political productions that are associated with activism, social movements, political protests, and cultural resistance.

Yet, memes have also been lately weaponized, hijacked, and exploited by hate groups, state-run trolls, and extremists to support their political agenda. Numerous studies examined this aspect of memes' use mostly by alt-right trolls and groups (Bay, 2018; Bogerts \& Fielitz, 2018; Dematagoda, 2017; Flisfeder, 2018; Hannan, 2018; Harmer \& Lumsden, 2019; Heikkilä, 2017; Woolley \& Guilbeault, 2017). For instance, Russian trolls actively used memes to target young people, mostly showing Western leaders as fascists, while Ukrainian soldiers were presented as Nazis with fake photoshopped images (Aro, 2016, p. 125). These types of memes are regarded as toxic because they carry different types of hate speech discourses (Coker, 2008, p. 911). However, empirical research on Instagram as well as on fake news discourses is not available despite the fact that a US Senate Intelligence Committee report indicated that Russian trolls actively used Instagram more than Facebook during the 2016 election (Frier \& Dennis, 2018). Hence, this study fills another gap in literature on the issue of toxic speech on Instagram.

In general, many of the US President Donald Trump's followers on Reddit were active in trolling and distributing 'dank memes' during the 2016 US election. These types of memes are characterized as low-quality images or videos whose main purpose is the dissemination of jokes. Engaged in the so-called 'Great Meme War,' those supporters call themselves 'keyboard commandos' whose goal is to "harass Trump's detractors and flood the Internet with pro-Trump, anti-Hillary Clinton propaganda" (Schreckinger, 2017). This was part of Meme War I that was meant to get Donald Trump elected (Roose, 2017) with the help of 'meme armies' that lately announced that Meme War II has already started (Roose, 2017) and is meant to keep Trump in power. In a recent study on Trump's followers on the subreddit / $r$ /The Donald (T D), the authors highlighted how fake news stories are widely circulated such as the one calling for action on the murder of the Democratic National Committee (DNC) employee Seth Rich, for his fatal incident was falsely linked to a conspiracy theory revolving around his connection to the DNC email leak (Flores-Saviaga, Keegan, \& Savage, 2018). Aside from Reddit, other social media platforms like 4chan received some scholarly attention regarding the study of Trump's trolls and their memes such as 'Trump Train' and 'You can't stump the Trump' (Merrin, 2019). Other popular memes include the far-right 'Pepe the Frog' and the
'Deplorables' ones which present Trump himself as Pepe the Frog figure (Hine et al., 2017; Merrin, 2019, p. 208). As a matter of fact, Trump promoted the meme of Pepe the Frog on his Twitter account in 2016 (Revesz, 2016), which assisted in making some of the alt-right symbols become mainstream (Davey, Saltman, \& Birdwell, 2018). In brief, the 'Great Meme Wars' are waging on different social media outlets in which political trolls from different ideological backgrounds try to exert their cultural power and control over the online discourses. Since there is a dearth of empirical research of political memes on Instagram, this study fills a few gaps in the academic literature. This study attempts to answer the following research questions:

RQ1: What is the nature of the main online communities that discuss fake news with Instagram's political memes?

RQ2: What are the dominant topics of fake news discourses in these memes?

\section{Method}

The data collection in this study was done in two stages. The first stage involved collecting 293,773 Instagram posts for the period between 30 September 2012 to 13 November 2018 using Netlytic academic subscription. However, when Instagram changed its Application Programming Interface rules in late 2018, the data collection stopped, so the researcher adapted a Python script that collected JSON file for each Instagram post using the search term \#fakenews. The search resulted in collecting 551,402 Instagram messages posted between 24 February 2012 to 21 December 2018 by 198,684 unique users (Figure 1). The Python script collected older data dating back to 2012 which referenced \#fakenews, while any deleted posts were not retrieved from the platform. In this regard, the highest number of posts ( $n=10,294$ ) were posted on October 21, 2018, which coincided with a tweet from President Donald Trump on the same day, stating: "Facebook has just stated that they are setting up a system to 'purge' themselves of Fake News. Does that mean CNN will finally be put out of business?" (Trump, 2018). The Python script has limitations, for it only collected Instagram posts that are available online, constituting about $50 \%$ of the total number of posts referencing \#fakenews on the platform.

After the data collection, a number of mixed methodological measures were followed to analyze the Instagram posts. First, topic modelling was used with the use of a commercial software called QDA MinerWordStat 8. Topic modeling is a machine learning language technique based on analyzing unstructured data. For our study, we used Non-negative matrix factorization (NNMF) approach which is a text mining method (Pauca, Shahnaz, Berry, \& Plemmons, 2004), often employed in investigating a variety of issues like topics identi- 


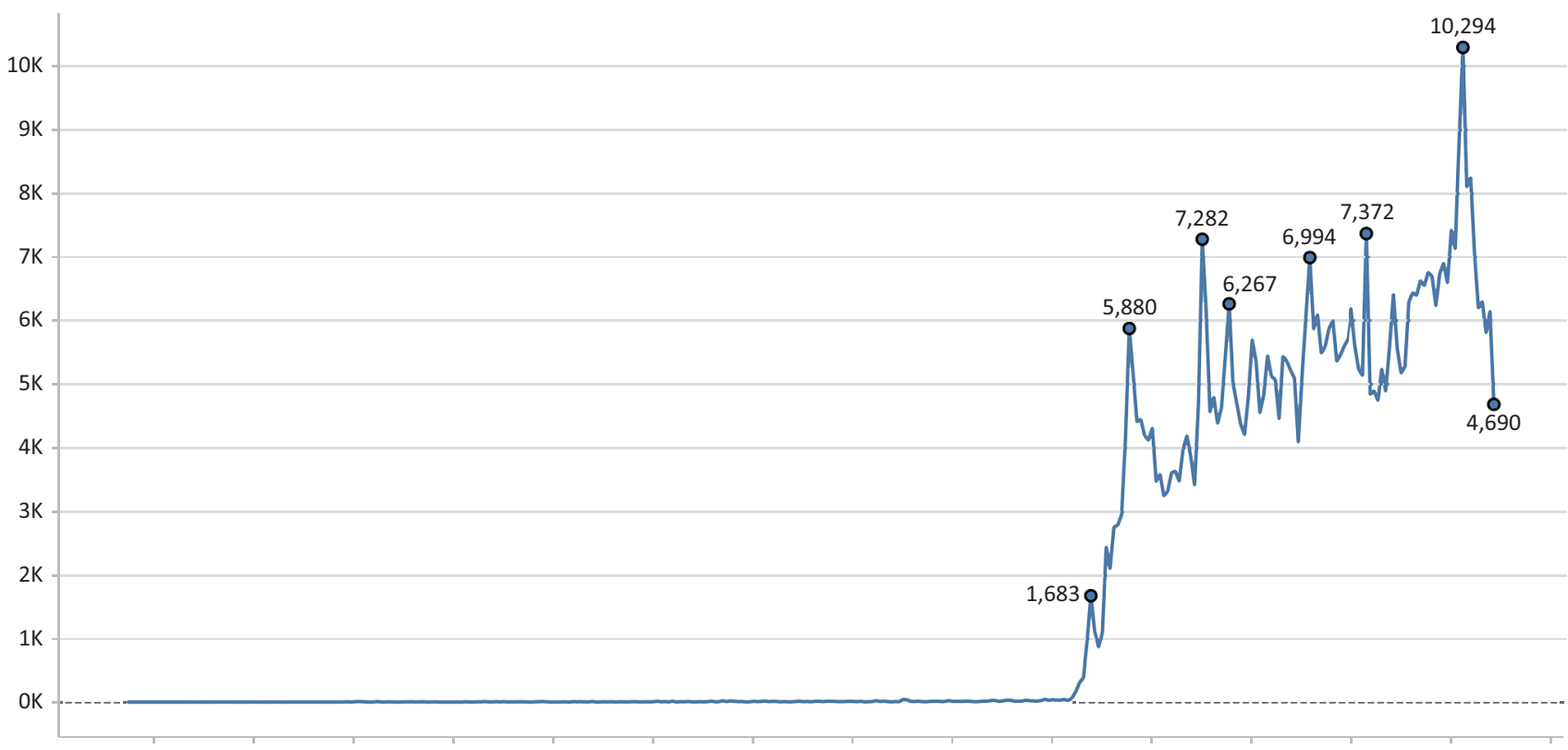

Apr 8,12 Oct 7, 12 Apr 7, 13 Oct 6, 13 Apr 6, 14 Oct 5, 14 Apr 5, 15 Oct 4, 15 Apr 3, 16 Oct 2, 16 Apr 2, 17 Oct 1, 17 Apr 1, 18 Sep 30,18

Figure 1. Timeline of Instagram posts distribution referencing \#fakenews.

fication and monitoring (Vaca, Mantrach, Jaimes, \& Saerens, 2014). NNMF topics were ranked based on their coherence which "refers to the overall quality and the semantic relatedness of the terms appearing in a topic descriptor" (Belford, Mac Namee, \& Greene, 2018 , pp. 8-9). The same computer software was used in identifying the most recurrent hashtags, user mentions, most recurrent words and phrases as well as their co-occurrences measured through proximity plots.

Second, we used pivot tables to identify the unique users though the process was tedious because the Python script only provides individual user ID numbers in JSON format, so the author had to convert the files in bulk into Excel and individually search for the top Instagram usernames on the platform. Using inductive coding, a qualitative examination of 20 users was initially conducted by two coders to examine any emerging categories (Wimmer \& Dominick, 2013), and three main online communities were identified, mostly centered around personalized discussion of famous individuals: (1) Pro-Trump, (2) Anti-Trump, (3) Bolsonarorelated, (4) Other. Intercoder reliability test was conducted using Krippendorf Alpha test ( $\alpha=1.0$.). From this representative sample, five accounts were initially suspended or deleted including three pro-Trump and two without clear affiliation. The latter category included users who have no clear political affiliation and often refer to \#dankmemes, while a few others focused on general news dissemination, conspiracy theories, marketing, and creative art and photography. Some of the irrelevant conspiracy theories promoted include the illuminati, veganism, UFOs, and the notion that earth is flat. These users were excluded from the study due to the diversity of their posts and their small numbers in the dataset. The third online community included five users dealing with the populist Brazilian President, Jair Bolsonaro, who posted in Portuguese, repeatedly adding the hashtag \#fakenews to their posts. This is another minor online community that is excluded from the study because the author is not familiar with Portuguese language. Afterwards, the top 100 most active users, who collectively sent 100,507 Instagram posts, were thoroughly examined by studying their online profiles, other Instagram posts if available, and the archived Instagram posts in case their accounts were deleted.

Ultimately, the study adds a unique aspect that has not been included before in fake news research on social media. In this regard, the computational analysis of a large number of images in media and communication discipline is rare, and this study attempts to fill a gap in literature especially in relation to Instagram research. We followed here the recommendation made by Highfield and Leaver (2016) who stress that "developing approaches to track and study the visual as widespread social media form, including across platforms as content is shared and reappropriated, is a necessary undertaking for a critical understanding of social media use" (p. 58). Out of the total sample of collected Instagram posts, there were 310,649 visuals (56.3\%) that were automatedly tagged by Instagram. The platform sometimes provides an automated description of images that includes thousands of categories like ' 1 person,' 'tree, snow, sky, table and outdoor,' or ' 3 people, meme, crowd and text.' These visual tags can appear if one hovers with the mouse over some but not all Instagram images. In our study, we found over 5,900 different tag categories. We textually analyzed these visual tags as well as 4,596 textual content $(0.8 \%)$ in these visuals (memes that contain text) in order to add more depth into our textual analysis. In this study, we found that fake news discourses on Instagram 
are more likely to include images $78.9 \%$ ( $n=435,387$ ), videos $14.3 \%$ ( $n=79,004)$, and less frequently sidecar images $6.7 \%(n=37,011)$, which refers to a series of photos posted by one user and dealing with a similar theme or event.

Finally, research ethics clearance was not required from the author's university because the social media data is publicly available. More importantly, informed consent from active social media users is not usually needed when conducting critical media research like the case study examined here that involves alt-right users (see Townsend \& Wallace, n.d., pp. 11-12).

\section{Results and Discussion}

This study focuses on the examination of political memes in relation to fake news discourses on Instagram. Its goal is to understand the nature of the active users and their online communities as well as the main topics discussed on Instagram since there is a gap in literature on this research aspect. To answer the first research question on the nature of the online communities on Instagram, we found that the most dominant online community among the top 100 most active users is the Pro-Trump one $(68 \%)$ followed by Anti-Trump (10\%) online community. A third minor online community is formed around the Brazilian populist President, Jair Bolsonaro (5\%). The Pro-Trump camp posted 69,630 messages constituting $69.2 \%$ of the total posts of the active users, while the Anti-Trump online community sent 14,061 ones which amounts to $13.9 \%$ only. Indeed, the Pro- and Anti-Trump users form the major Instagram communities which discuss fake news, and what makes them distinctive and unique is the personalized praise as well as attacks or trolling activity against individual politicians. This has been evident not only in the qualitative investigation of the most active users presented above and in the following paragraph but also the examination of the top posts, most recurrent words and phrases, and more importantly the large data analysis of the accompanying images.

Regarding the visual tags, Figure 2 provides a representation of the top 50 most popular image descriptions, and we found that the top one is related to images containing ' 1 person' ( $n=71,876$ ) followed by images with 'text' $(n=36,508)$, ' 1 person, text' $(n=30,650)$, '2 people' $(n=24,134)$, and ' 2 people, text' $(10,201)$. As can be seen, there is a personalized type of messages in these visual discourses that mostly deal with one person, which explains the prevalence of certain individuals in the textual discourses about fake news on Instagram. In fact, the total number of images containing one person in different formats is 136,716 , constituting $44 \%$ of the total tagged images. This is the highest percentage among all the other visual tags.

As for the visual analysis, we agree with Highfield and Leaver's (2016) assertation that the "visual is central to everyday life and social media practices" (p. 49). In this study, we found that Donald Trump is the main focus of the visual discussion, for he is part of the most frequent phrase $(n=338)$ if one takes into account the combination of the two phrases 'Trump Realdonaldtrump' ( $n=173$ ) and 'Donald Trump' $(n=165)$. The same emphasis is found in the most frequent words in the image texts, for 'Trump' comes first $(n=1229)$ if one ignores the basic tag words like 'text,' 'person,' and 'people,' and without taking into account the word 'Realdonaldtrump' $(n=220)$. Other popular politicians include 'Obama' $(n=165)$ and Clinton $(n=129)$, while the recurrent phrases include 'Hillary Clinton' $(n=66)$ and 'Ben Shapiro' ( $n=53$ ), the famous conservative commentator. Once again, this finding confirms the discussion above on the personalized type of discussion on fake news which is evident in the visual findings as well as the textual analysis presented below.

To further understand these two main online communities, we provide here more in-depth analysis of some of the top 20 most active users (Table 1). These users consist of a majority of pro-Trump Instagrammers $(n=17)$ and only a couple of anti-Trump ones as well as one with no clear affiliation. This table clearly indicates the dominance of the pro-Trump community who regard themselves as meme warriors, as mentioned above. Such users often use a long list of hashtags in order to spread their memes as far as possible which includes several themes like praise for their community leaders and members (\#Rarepepe, \#Kekistan, \#Praisekek, and \#kek), attacks against democrats and liberals (\#liberalsSuck, \#liberaltears, \#draintheswamp, and \#libtards), support for Donald Trump (\#MAGA, \#IsMyPresident, \#buildthewall, \#trumptrain, and \#Trump2020; see Figure 3), and criticism against liberal mainstream media especially CNN (\#CNNisFakenews and \#fakenews). These results are actually similar to a similar investigation on Twitter that examined the hashtag \#fakenews (Al-Rawi, 2019a). Regarding the last theme, the majority of users in this community express doubts and mistrust in mainstream media such as the case of the user @stoppingtheabuse who describes himself as follows: "I am a patriot. I am a proud American. I am white. I am Christian. I am a republican....I don't listen to fake news."

To examine a few top users from this community, the 7th most active Instagrammer calls himself “@Captain_Kekistan” which is a reference to the Hollywood superhero, Captain America, and it is also evident in the user's profile that refers to the same character though (s)he changed the color into green (Figure 4). As for 'Kekistan,' it is a popular far-right term which is based on a coded language used among this community who believe in conspiracy theories like QAnon (Al-Rawi, 2020; Merrin, 2019). The latter is a conspiracy theory term that implies the existence of a deep state in the US whose goal is allegedly overthrowing or undermining Donald Trump's presidency (Al-Rawi, 2020). Another example of a Pro-Trump user, conservative_americans posts similar Instagram messages with those periodically sent by Captain_Kekistan. The user's full name 


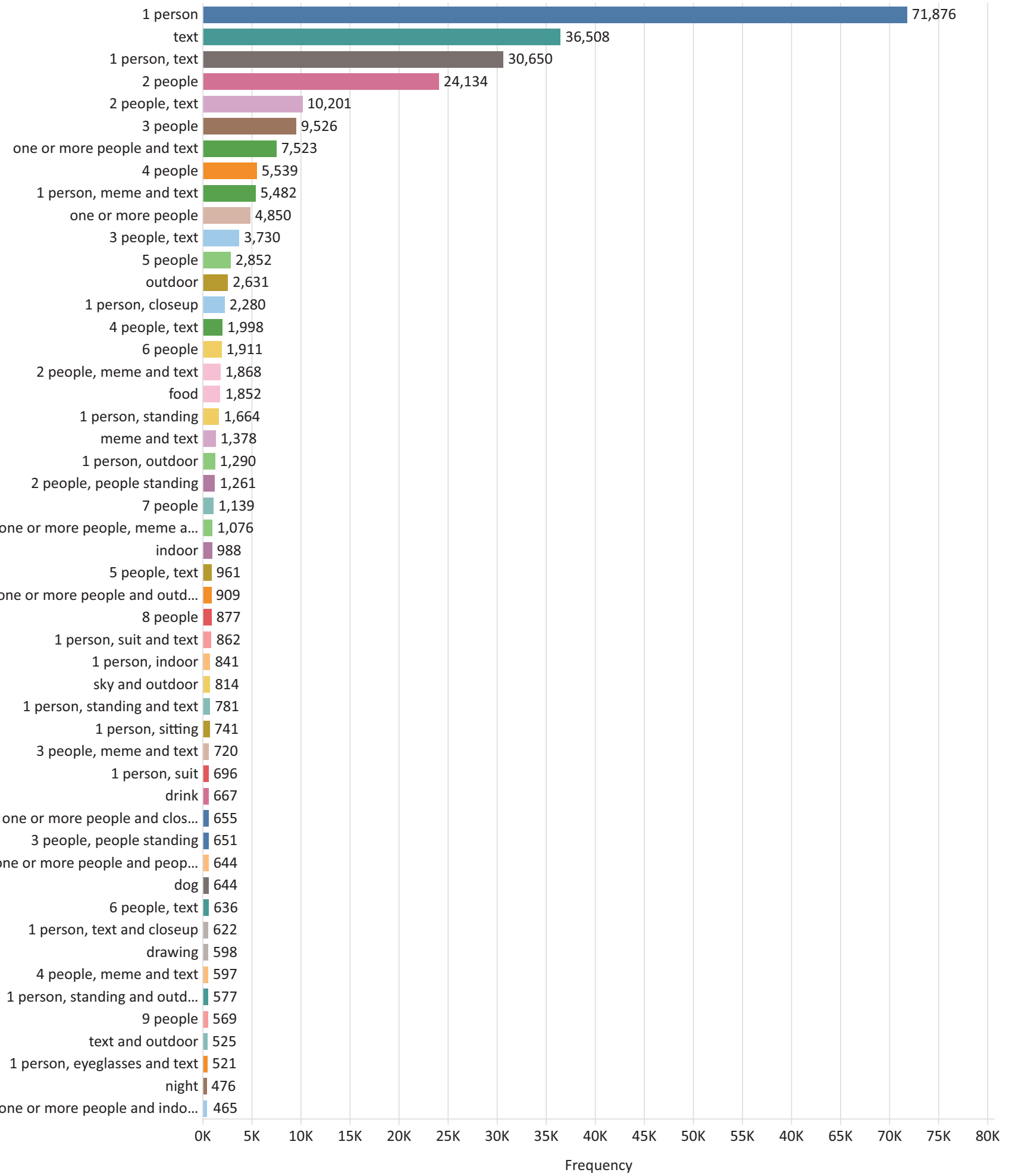

Figure 2. The top 50 most associated Instagram's visual tags.

is 'Right Wing Meme Factory,' denoting the purpose of this account. Interestingly, the user's online account shows only four messages though (s)he sent 1399 posts archived in our dataset which means that (s)he periodically deletes messages probably to avoid detection or removal by the platform. This is also a social media strategy used by drug dealers (Al-Rawi, 2019b) and state-run users (Al-Rawi \& Shukla, 2020) to spam others while making sure their online presence remains active on social media platforms. I call these users 'sleeper cells' because they get activated when needed. After performing their required duties, they disguise themselves again by removing all their public messages. Another way of avoiding detection is by keeping the account private such 
Table 1. The top 20 most active users on Instagram in relation to \#fakenews.

\begin{tabular}{llr}
\hline No. & Username & Frequency \\
\hline 1. & alternative_news_media & 10,426 \\
2. & breakupartist & 5,620 \\
3. & conservative_warrior__ & 4,419 \\
4. & maxcua & 2,610 \\
5. & unfiltered.politics & 2,550 \\
6. & onyxnegus & 2,314 \\
7. & captain_kekistan & 1,896 \\
8. & only_conservative__obomb & 1,755 \\
9. & deplorable_brandysthebomb & 1,726 \\
10. & usa_stands_in_honor_- & 1,612 \\
11. & lepetersworld & 1,566 \\
12. & thetrumpphenomenon & 1,561 \\
13. & thedukesofdonaldtrump & 1,504 \\
14. & this.mom.is.right & 1,485 \\
15. & bigleaguetrumpster & 1,407 \\
16. & dmone_fat & 1,404 \\
17. & conservative_americans & 1,399 \\
18. & doomedamerica & 1,325 \\
19. & vertical_stance & 1,283 \\
20. & universal_enlightenment & 1,142 \\
\hline
\end{tabular}

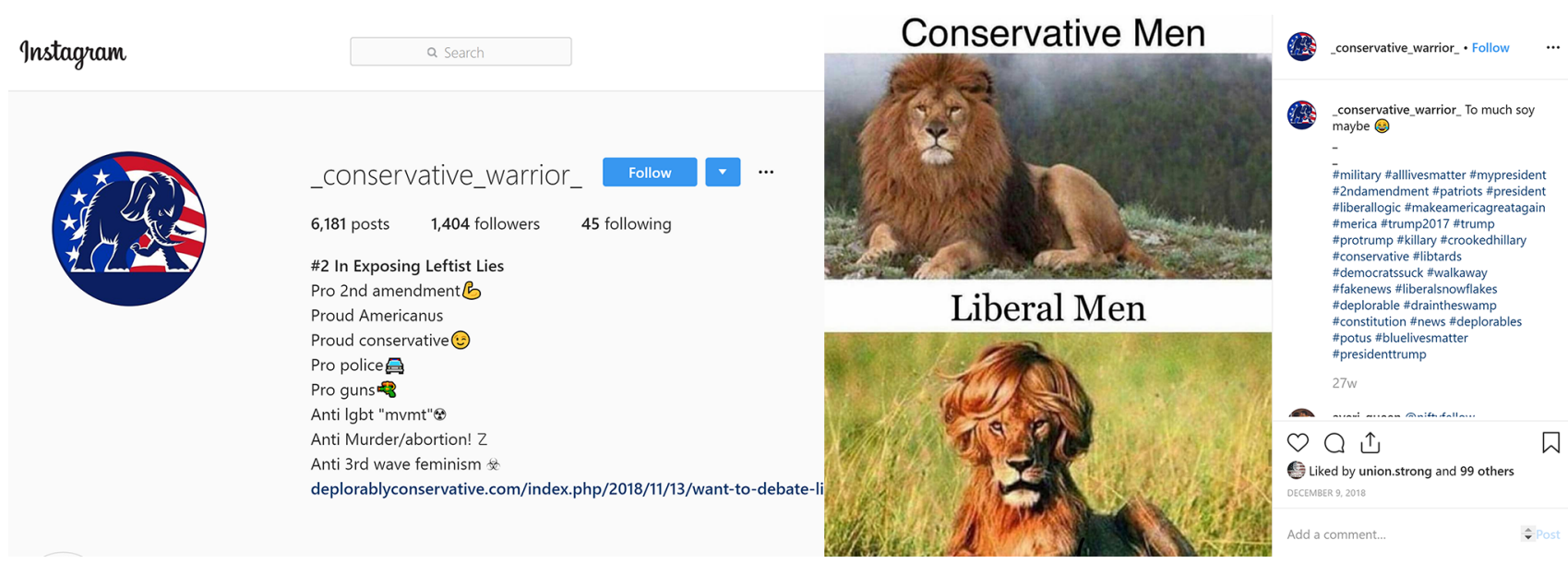

Figure 3. A screenshot of a Pro-Trump follower using the hashtag \#fakenews (https://www.instagram.com/_conservative_ warrior_?hl=en).

When the DNC screws over Bernie again and all of his supporters have no option but to vote for Trump
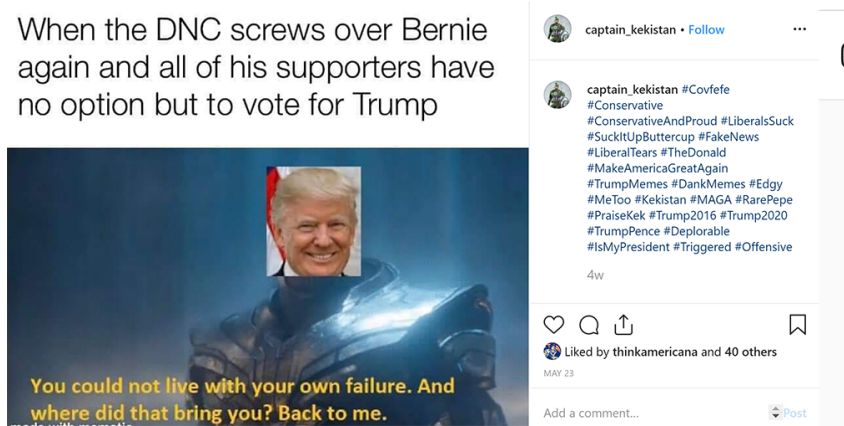

(0) | Instagram

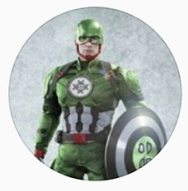

captain_kekistan

2,059 posts

1,152 followers

\#Captain Kekistan

The alt-right shitposting man with a plan. PRAISE.KEK

Figure 4. Screenshots of Captain_Kekistan on Instagram (https://www.instagram.com/captain_kekistan/?hl=en). 
as the case of @conservative.comedy that posted 705 Instagram messages as well as @but_muh_clownshow that is discussed below. Some of the other general features of this online community are its positions on several issues such as anti-immigration, distrust of Muslims, nationalism, protectionism, and xenophobia. For instance, @pjb101263 posted 597 Instagram messages referencing \#fakenews including the following one that shows the US Congresswoman, Ilhan Omar, flying an airplane towards what appears to be the twin towers (Figure 5). Another feature that some users in this online community employ is anti-Semitic discourses which are manifested in several ways including the use of far-right hashtags (see above), emojis like 909 that was used 794 times, and the triple parentheses or echoes (Williams, 2016). In our dataset, we found the echoes used 213 times in the public discourses on fake news. For example, @trumpmemz user mentions that Elon Musk is triggering Jewish mainstream journalists for his alleged plan to create a ranking website for journalists' credibility.

While the study is being written, two more ProTrump accounts were deleted by Instagram including @vertical_stance and @excuse_me_excuse_me_. It is not clear why the accounts were removed, though. Similar accounts shortly emerged like vertical_stance2.0 whose original motto is 'Exposing the mainstream media' and 'Journalism is dead.' As for @excuse_me_excuse_me_, the user acts like a troll who has been repeatedly blocked and deleted, stating: "My dear conservative friends (-) I I have made a second account, just in case. (-) This will remain my main page, but feel free to follow the other one @excuse_me_excuse_me_." The user coordinates with similar trolls in attacking liberal users. One post, for instance, praises the collective efforts directed at a par- ody account of Hillary Clinton, mentioning: "Guys, you really hit that profile! @hillarry_clintton post can't be commented any more, so....Good job!

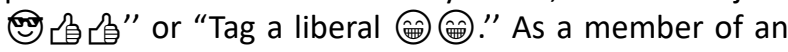
active online community, this user repeatedly urges his friends and followers to target democratic leaders like the real account of Hillary Clinton: "F)

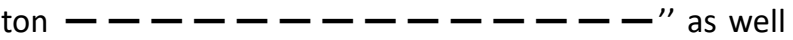
as follow other active users or influential in the community, stating: "Follow my partners: @thetrump phenomena 10 @usa_everyday 10 @authentic donaldjtrump I Similarly, numerous other users like @stoppingtheabuse and @conservative.comedy encourage their friends to re-post favorable messages and follow other members in the community by listing their Instagram usernames. This technique is similar to the Swarmcast model in communication wherein affiliated users gather around their opponents to attack them (Al-Rawi, 2018, p. 743). In brief, there is a clear coordination of organized efforts to identify and troll liberals on Instagram in order to silence or limit their activities. It is important to mention here that it is not possible to know whether these coordinated trolling activities are centralized or not as they can be organically driven by conservative fans and followers.

On the other hand, the anti-Trump online community on Instagram, which is much smaller and less organized than the Pro-Trump one, is often involved in trolling Republicans and the far-right group. Some of the popular hashtags used by this anti-Trump community include \#Blacklivesmatter, \#Resist, \#Dumptrump, \#Fucktrump, \#Notmypresident, \#Makeamericablueagain, \#Obama care, \#LGBTQ, and \#Progressive. To take a couple of examples, the second top user @Breakupartist ( $n=5,620$ ) almost always trolls Donald Trump and
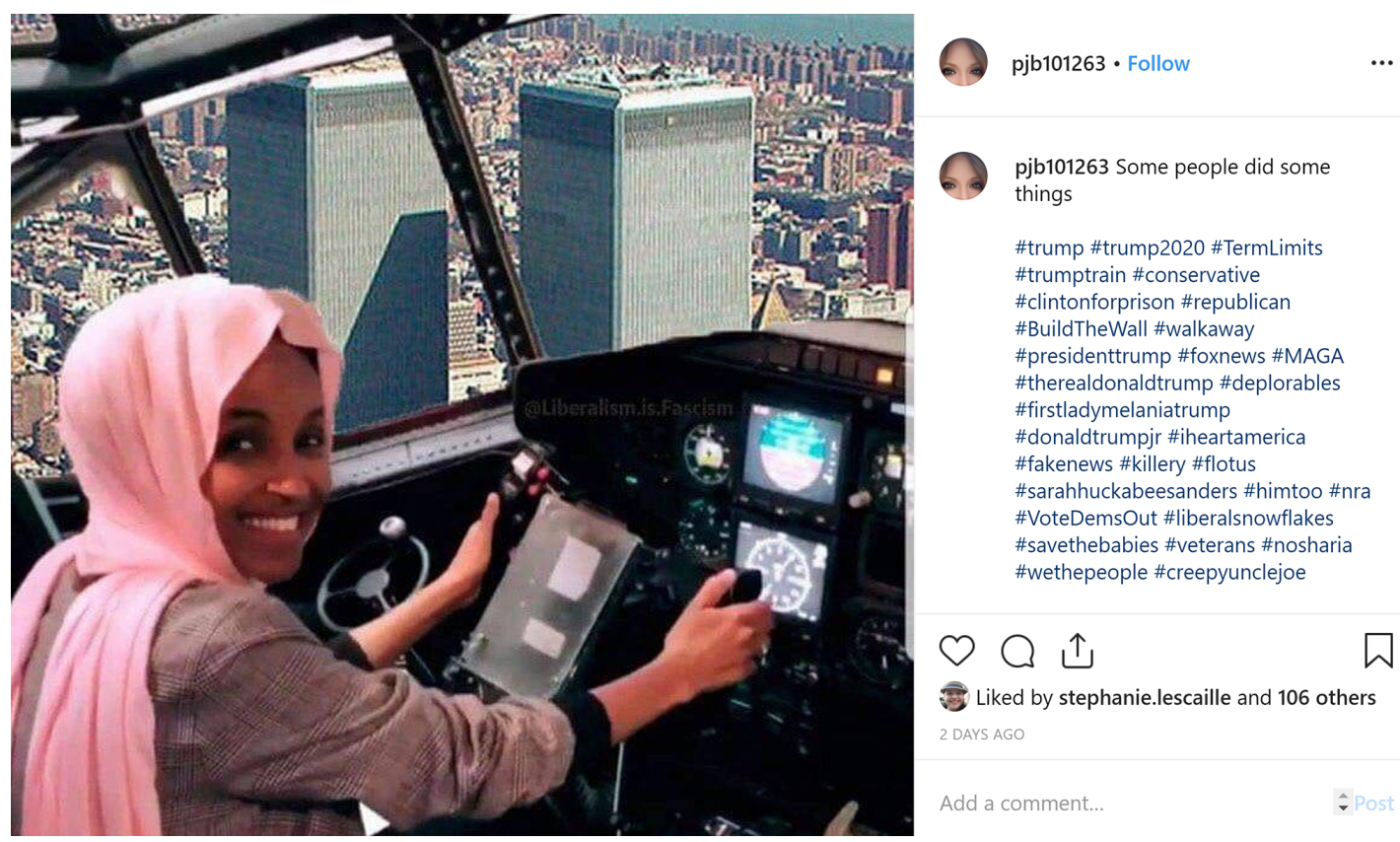

Figure 5. A photoshopped image showing Congresswoman Ilhan Omar as a 9/11 attacker. 
his administration, sometimes using offensive language similar to the discourse used by the Pro-Trump community. In Figure 6, we find that Trump was photoshopped to make him look like Hitler, while the US President logo sign was appropriated to read 'Moron of the United States' and MOTUS instead of POTUS. In addition, the image designer used the triple parentheses or echoes as a gesture of resistance against antiSemitic trolls and in solidarity towards Jews (Williams, 2016). Another user, @ledsjam_trump, sent 450 messages on fake news, describing himself as follows in his profile: "No Drumpf....Non-Stop! I'm the $400 \mathrm{lb}$ troll in my parents' basement, that you've heard about. QDedicated to Mocking Our Nation's Highest Ranking Buffoon. Homemade. RESIST!" (Figure 6).

To sum up, there are two distinct online communities that are active in relation to the discourses about fake news on Instagram. Each community trolls each other, but the pro-Trump one is more active and visible which is apparent in their organized efforts, total frequency of their posts, and prevalence in the top 100 most active users. The active members of these two communities regard themselves as activists who have a duty to counter the hegemony and attack the credibility of their opponents, and the ultimate goal is to control the discourses, gain more followers and sympathizers, and possibly influence the minds of Instagram users through the use of appealing, witty, and funny political memes. The results of this study align with previous research on the role of memes in enhancing community ties and creating a collective identity (Shifman, 2012) especially that sharing certain memes is a reflection of the ideological affiliation of some online communities and their gatekeeping practices (Burgess, 2008; Miltner, 2014). In addition, the political polarization that separates the two main communities is translated into tense and often toxic Instagram content that is often described as an ongoing "memes warfare" (Al-Rawi, 2020; Häkkinen \& Leppänen, 2014). Again, this is in line with previous research that examined social media and political polarization (Bay, 2018; Heikkilä, 2017) such as some polarized social media content posted during the 2016 US election (Denisova, 2019).

To answer the second research question on the main topics on Instagram in relation to fake news discourses, we find that the top five topics and their associated descriptors include four that are related to the Pro-Trump online community including Alllivesmatter, Rightwing, Draintheswamp, Republican, and only one relevant to the anti-Trump camp which is Notmypresident (Table 2). To provide more context, we will explore only a few ones here due to the limited space. The first topic is Allivesmatter which is a term used by some conservatives to counter the claims of the Black Lives Matter movement. The use of this term suggests that all Americans including whites and police forces should be given equal weight and importance when it comes to issues of social justice and equality, ignoring the systemic injustice and historical circumstances that created economic and political inequality in the first place. Some of the associated words with this topic include a clear attack against Democrats with the word 'Liberallogic' to demean their arguments as well as other supportive terms like MAGA and Makeamericagreatagain. Criticism against liberals is also manifested in the third topic which is entitled 'Drain the Swamp,' a political term modified by President Trump to attack his Democratic opponents and accuse them of corruption and ineptness (Bierman, 2018). In relation to this topic, we find that some of the associated terms include Antifa, the anti-Fascist movement that is often the object of attacks by far-right groups, as well as CNN and its constant association with fake news. In fact, Trump encouraged his followers to troll CNN by sending funny or critical memes and videos (Gallagher, 2019). On the other hand, there are also words that show solidarity and unity among the Pro-Trump community members like MAGA, Mypresident, Deplorable, that was appropriated from
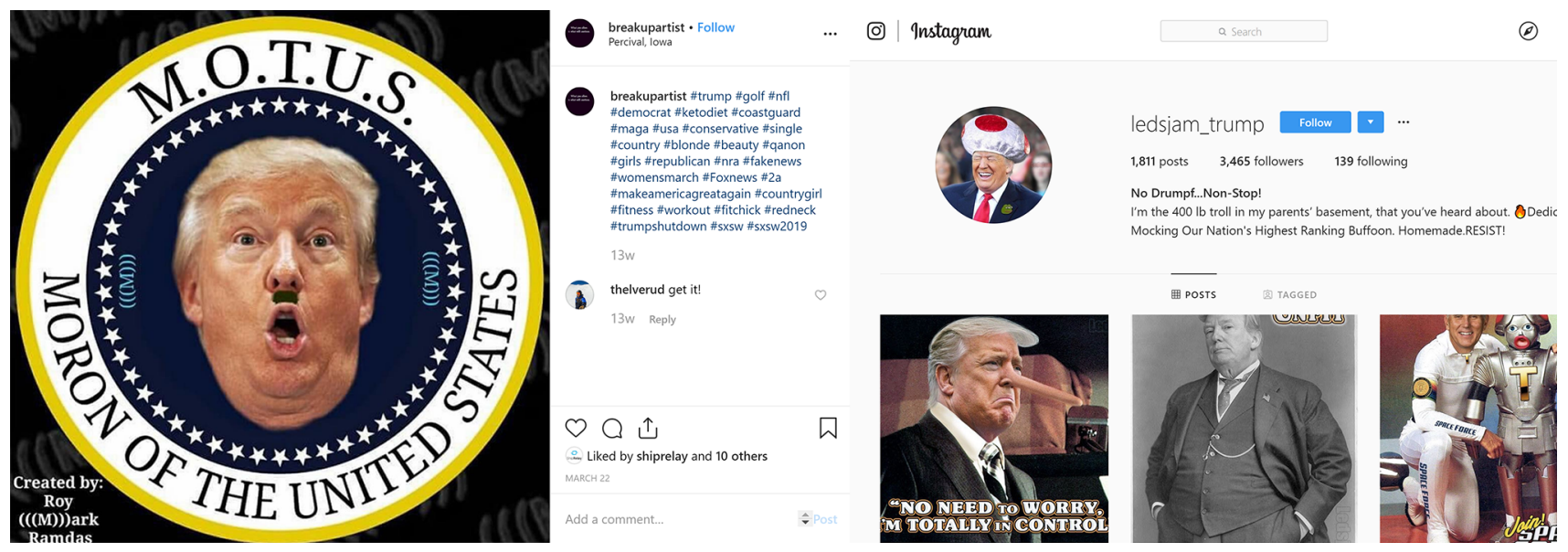
Im the $400 \mathrm{lb}$ troll in my parents' basement, that you've heard about. ODed Mocking Our Nation's Highest Ranking Buffoon. Homemade.RESIST
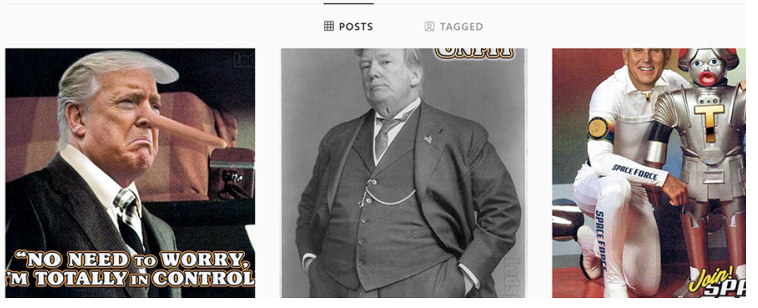

Figure 6. Anti-Trump Instagram users trolling Trump using \#fakenews (https://www.instagram.com/ledsjam_trump/ ?hl=en). 
Table 2. The major topics on Instagram in relation to \#fakenews.

\begin{tabular}{llc}
\hline Topic & Keywords & Coherence \\
\hline Alllivesmatter & Allivesmatter; Constitution; Media; Democrats; Media; Liberallogic; Meme; \\
& La; Bluelivesmatter; Partners; Makeamericagreatagain; Para; Patriot; \\
& Donaldtrump; Memes; MAGA; Conservative; Republicans & 0.514 \\
Rightwing & Rightwing; Para; LOL; Time; Maga; Donaldtrump; Patriot; Deplorable; Republicans; & 0.497 \\
& Americafirst; America; President; Buildthewall; Conservative; Liberallogic; Fake; \\
& Makeamericagreatagain; CNN; La; Bluelivesmatter; Patriots; God; Republican; \\
& Politics; Follow; Media; Democrats; Meme; Partners \\
Draintheswamp & Draintheswamp; Merica; Qanon; Fakenews; Realdonaldtrump; Antifa; Follow; \\
& CNN; Deplorable; MAGA; De; Fake; Mypresident; America \\
& Real; Republican; Resist; Buildthewall; Bluelivesmatter; Americafirst; American; \\
& Media; La; Makeamericagreatagain; Donaldtrump; Rightwing; Patriot; Maga; \\
& President; Conservative; Deplorable; LOL; Media; Republicans \\
& Government; Notmypresident; Foxnews; De; America; Media; GOP; President; \\
& Deplorable; God; Constitution; Meme; Rightwing; Americafirst; Real; \\
Conservative; Resist; Time; Para; Make; Donaldtrump; LOL
\end{tabular}

Hillary Clinton's 2016 interview (Caffier, 2017), Merica instead of America which is often used in popular culture discourses to express patriotism, and Qanon.

To further investigate the main topics, we examined the most recurrent words to understand the salience of some terms that carry political or cultural meanings. Aside from the common words like 'fakenews' and 'fake,' Table 3 shows the top 50 most recurrent words and we can find that 'Trump' ( $n=271,241$ ) comes second due to his dominance in the discussion by the two main online communities. Yet, most of the discussion is supportive of the US President because the subsequent words that follow Trump are mostly related to his party and policies like 'MAGA'

Table 3. The most frequent words used in the Instagram posts on fake news.

\begin{tabular}{|c|c|c|c|c|c|}
\hline No. & Word & Frequency & No. & Word & Frequency \\
\hline 1. & Fakenews & 498,527 & 26. & People & 35,601 \\
\hline 2. & Trump & 271,241 & 27. & Meme & 34,143 \\
\hline 3. & MAGA & 128,505 & 28. & Funny & 34,006 \\
\hline 4. & Conservative & 123,527 & 29. & Buildthewall & 32,962 \\
\hline 5. & News & 117,173 & 30. & Truth & 32,469 \\
\hline 6. & Republican & 89,493 & 31. & Liberallogic & 32,037 \\
\hline 7. & Donaldtrump & 89,113 & 32. & Repost & 31,366 \\
\hline 8. & CNN & 85,730 & 33. & Merica & 29,365 \\
\hline 9. & Makeamericagreatagain & 84,974 & 34. & Obama & 28,439 \\
\hline 10. & America & 81,886 & 35. & Trumpmemes & 26,056 \\
\hline 11. & USA & 68,445 & 36. & Bluelivesmatter & 26,003 \\
\hline 12. & Fake & 62,789 & 37. & Russia & 25,456 \\
\hline 13. & Follow & 60,875 & 38. & Resist & 25,374 \\
\hline 14. & Politics & 56,493 & 39. & Democrats & 25,231 \\
\hline 15. & Trumptrain & 53,447 & 40. & Liberals & 24,857 \\
\hline 16. & Memes & 51,352 & 41. & American & 24,127 \\
\hline 17. & Liberal & 47,452 & 42. & Love & 23,764 \\
\hline 18. & Draintheswamp & 46,622 & 43. & Ndamendment & 23,613 \\
\hline 19. & Presidenttrump & 45,107 & 44. & Freedom & 23,026 \\
\hline 20. & Democrat & 40,692 & 45. & Patriot & 22,954 \\
\hline 21. & Foxnews & 40,152 & 46. & Libtards & 22,735 \\
\hline 22. & Potus & 40,071 & 47. & Military & 22,556 \\
\hline 23. & President & 39,895 & 48. & Notmypresident & 21,774 \\
\hline 24. & Media & 38,803 & 49. & Partners & 21,469 \\
\hline 25. & Americafirst & 38,330 & 50. & GOP & 21,416 \\
\hline
\end{tabular}


(Make America Great Again), 'conservative,' 'republican,' 'Donaldtrump,' 'Makeamericagreatagain,' 'Trumptrain,' 'Americafirst,' 'Buildthewall,' 'Bluelivesmatter' etc. At the same time, there are many words used that indicate trolling activity or attacks against liberal democrats like 'Draintheswamp,' 'Liberallogic,' and 'Libtards.' On the other hand, the top 50 words only show two words that are often used by the anti-Trump online community including 'Resist' ( $n=25,374)$ and 'Notmypresident' $(n=21,774)$, which indicates the minor presence of this online community.

In terms of media outlets, two channels are referenced in the list of top terms including CNN $(n=85,730)$ and Fox News ( $n=40,152$ ). To further understand how these outlets are used in the online discussion, we examined the most recurrent phrases or combination of words. In this regard, two of the most recurrent phrases are 'CNN fakenews' ( $n=18382$ ) and 'Fakenews CNN' $(n=14511)$ that are used by the Pro-Trump online community. We also examined the co-occurrence of the word 'CNN' and found that it is firstly connected with the term 'fakenews' ( $\mathrm{n}=72,765$ ) with a very strong association $(<0.901)-1$ is complete and 0 has no association. To a lesser extent, we find other phrases that indicate opposition to the Trump's administration including 'Fakenews Dumptrump Nevertrump' ( $n=5924)$ and 'Fakenews Dumptrump Nevertrump Resist Fucktrump' ( $n=5866$ ).

To corroborate the above findings, we further examined the most mentioned users in the online discussion. Similar to the above findings, we found that President Donald Trump comes first as the most mentioned user ( $n=10,743$ ) immediately followed by CNN ( $n=5,768$ ). In the top 20 most referenced users, Trump's son, @Donaldjtrumpjr, is also among the most referenced as well as three other liberal mainstream media outlets including the New York Times, Washington Post, and ABC, while Fox News comes near the end of the list. The only other politician included in the list is the Brazilian president, @Jairmessiasbolsonaro, and two of his sons Eduardo, @bolsonarosp, and Flavio, @flaviobolsonaro. In total and aside from five mainstream media outlets, there are nine Pro-Trump users, three Bolsonaro-related users, two deleted accounts, and one irrelevant one. Similar to the discussion found above, some active Pro-Trump users mention other ones in their community to get support such as @Teentrumpsupporter who lists 13 other Instagrammers as 'partners.' Other users with deleted accounts create similar profile names by sometimes adding a number, letter, or word to the original username. For example, after@But_Muh_Russia got deleted from Instagram, the user created @but_muh_clownshow, describing himself as follows: "(((They))) are scared of you. Nothing is more powerful than the public being awake and collectively free- thinking! Formerly @ but_muh_russia." In addition to the anti-Semitic use of the echoes, the image profile uses the far-right symbol of Pepe the Frog as well as a hidden lynching noose that is reminiscent of the slavery era though this time it looks like an implied threat against the LGBTQ community. This is evident in the head cap the Frog is wearing (Figure 7), for this clown pepe figure is often called Honk Honk or Honkler in popular culture and is intentionally used in an attempt to reclaim the rainbow symbol from the LGBTQ community (Jhaveri, 2019; Know Your Meme, 2018).

As for the visual analysis, we decided to combine more than one approach in the examination of visuals because it becomes a more effective method in understanding images (Rose, 2016, p. 99). As memes contain text embedded in the images, we decided to examine it. Aside from the word 'Trump' and a few other politicians
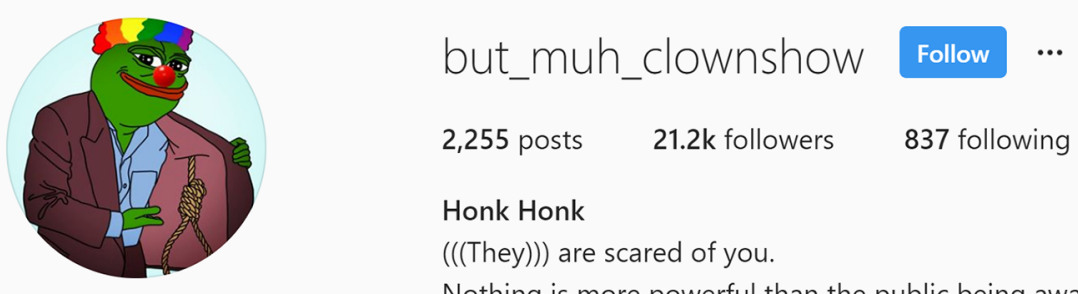

Honk Honk

(((They))) are scared of you.

Nothing is more powerful than the public being awake and collectively free- thinking!

Formerly@but_muh_russia

This Account is Private

Follow to see their photos and

videos.

Figure 7. A Pro-Trump user on Instagram expressing implied threats. 
mentioned above, we found that other frequent words and phrases in these memes include ' $\mathrm{CNN}^{\prime}(\mathrm{n}=253)$ which is the top channel targeted followed by 'Fox News' ( $n=105)$ and 'Media Is Fake News' $(n=34)$. This indicates the nature of visual attention to these two channels by the two online communities each accusing the other of being a fake news outlet. In this regard, we examined the co-occurrence of the words 'ABC,' 'CNN,' 'Fox,' and ' $M S N B C$ ' in the visual texts and found that ' $C N N$ ' is firstly and mostly linked to 'fakenews.' In fact, the terms 'fake' co-occurs 28 times with 'CNN' $(<0.015$ association), 6 times with 'ABC,' 3 ones with 'NBC,' and 3 others with 'Fox.'

As for the other visual tags analysis, some of the identified objects can be relevant like 'stripes' which refer to the US flag, mostly denoting nationalistic expression through memes. This is, in fact, not unique to the US context, for using one's national flag is similar to the 'cybernationalism' sentiments expressed by some Chinese Instagram users (Fang, \& Repnikova, 2018, p. 16). In our dataset, the US flag was used 790 times in these visuals in 9 different formats like ' 1 person, stripes' $(n=140)$, 'stripes and outdoor' ( $n=66)$, 'standing and stripes' $(n=50)$, 'stripes and text' $(n=33)$. The qualitative assessment of a sample of these visual posts involving the US flag shows that the majority are Pro-Trump followers though there are different other users discussing it mostly to express nationalistic sentiment like the following user: "I'm a proud American. Are you?\#MAGA\#Trump \#Bigdon\#Thedon\#Buildthewall\#Makeamericagreatagain \#Crookedhillary\#Draintheswamp," while another one stated: "I love this country! Thank God we have a great President who fixing it! Look how beautiful our flag is! \#MAGA" [sic].

Another aspect that requires analysis is the examination of the most recurrent posts that are used in the online discussion. Aside from the neutral, irrelevant, and ambiguous messages, we find that 15 out of the 20 top posts are part of the Pro-Trump online community that shares supportive hashtags on Donald Trump like \#Trump2020 and \#LoveTrump including some that are critical of mainstream media. For instance, the fifth most frequent post $(n=536)$ partly reads as follows: "\#EnemyOfThePeople = @nytimes = \#fakenews $/$ fascists \#EnemyOfThePeople = @cnn = \#fakenews $/$ fascists \#EnemyOfThePeople = @washingtonpost = fakenews \#fascists \#JeffSessions = \#EnemyOfThePeople @thejusticedept = \#EnemyOfThePeople @abcnetwork = Nazis \#WalkAway."

The same applies to the top 20 most commented on posts that include 9 out of 20 Pro-Trump messages which received 79,425 comments. On the other hand, there are only two anti-Trump posts that received 9,132 comments, while the other most commented on posts are neutral or did not show a clear political affiliation. Regarding the latter anti-Trump community, one of the top most commented on posts includes a call to follow other similar users in the community, stating: "Go fol- low my partners: @_proud_liberal_, @texansocialdem, @the_norwegian_social_democrat...etc." This is, indeed, a tactic that is similar to what the Pro-Trump community follows.

To conclude, the visual and textual examination of fake news discourses on Instagram shows two highly polarized online communities separated by opposite political alliances. These two online communities exchange political memes that are mostly centered around individual prominent politicians especially the US President Donald Trump. However, the Pro-Trump community is much larger, more active, and organized than the anti-Trump community. At the same time, some active virtual 'warriors' of the Pro-Trump community show sympathy or affiliation with the far-right by using their hate and racist icons like Pepe the Frog, while expressing distrust in liberal mainstream media especially CNN. These findings indicate that Instagram has become weaponized by the two main online communities, and memes are used in an ongoing political online warfare to attack and demean the opponents. Meme War II is an ongoing daily reality on Instagram which requires more scholarly attention.

Finally, future research on fake news discourses need to include other under-researched visual platforms like Pinterest and Flickr in order to examine the nature of online communities and political memes that exist on these social media venues. In addition, in-depth interviews with members of the different Meme War communities need to be conducted to further understand their political strategies that are employed on Instagram and possibly elsewhere. Also, cross-national comparative research is vital, for this study identified an online community that is centered around the figure of the Brazilian President, Jair Bolsonaro, so it is important to understand how fake news discourses are used by the active members of this community.

\section{Acknowledgments}

This study is partly funded by a SSHRC Insight Development grant entitled "Fake News Perceptions and Discourses on Social Media and Canadian Mainstream Media." Grant no.: 430-2019-00100.

\section{Conflict of Interests}

The author declares no conflict of interests.

\section{References}

Al-Rawi, A. (2018). Video games, terrorism, and ISIS's Jihad 3.0. Terrorism and Political Violence, 30(4), 740-760.

Al-Rawi, A. (2019a). Gatekeeping fake news discourses on mainstream media versus social media. Social Science Computer Review, 37(6), 687-704.

Al-Rawi, A. (2019b). The fentanyl crisis \& the dark side of 
social media. Telematics and Informatics, 45, https:// doi.org/10.1016/j.tele.2019.101280

Al-Rawi, A. (2020). Kekistanis and the meme war on social media. The Journal of Intelligence, Conflict, and Warfare, 3(1), 13-13.

Al-Rawi, A., Groshek, J., \& Zhang, L. (2019). What the fake? Assessing the extent of networked political spamming and bots in the propagation of \#fakenews on Twitter. Online Information Review, 43(1), 53-71.

Al-Rawi, A., \& Shukla, V. (2020). Bots as active news promoters: A digital analysis of Covid-19 Tweets. Information, 11(10), 461.

Aro, J. (2016). The cyberspace war: Propaganda and trolling as warfare tools. European View, 15(1), 121-132.

Bay, M. (2018). Weaponizing the haters: The Last Jedi and the strategic politicization of pop culture through social media manipulation. First Monday, 23(11).

Bayerl, P. S., \& Stoynov, L. (2016). Revenge by photoshop: Memefying police acts in the public dialogue about injustice. New Media \& Society, 18(6), 1006-1026.

Belford, M., Mac Namee, B., \& Greene, D. (2018). Stability of topic modeling via matrix factorization. Expert Systems with Applications, 91, 159-169.

Bierman, N. (2018, February 9). Trump shifts meaning of 'Drain the Swamp' from ethics to anything he objects to. Los Angeles Times. Retrieved from https://www.latimes.com/politics/la-na-pol-swamp20180209-story.html

Bogerts, L., \& Fielitz, M. (2018). “Do you want meme war?" Understanding the visual memes of the German far right. In Maik Fielitz \& Nick Thurston (Eds.), Post-digital cultures of the far right: Online actions and offline consequences in Europe and the US (pp. 137-153). Berlin: Majuskel Medienproduktion $\mathrm{GmbH}$.

Burgess, J. (2008). 'All your chocolate rain are belong to us'? Viral video, YouTube and the dynamics of participatory culture. In G. Lovink \& S. Niederer (Eds), Video vortex reader: Responses to YouTube (pp. 101-109). Amsterdam: Institute of Network Cultures.

Burroughs, B. (2013). FCJ-165 Obama trolling: Memes, salutes and an agonistic politics in the 2012 presidential election. The Fibreculture Journal, 22. Retrieved from https://twentytwo.fibreculturejournal.org/wpcontent/pdfs/FCJ-165Benjamin\%20Burroughs.pdf

Caffier, J. (2017, February 9). Every insult the left uses to troll conservatives, explained. Vice. Retrieved from https://www.vice.com/en_ca/article/wn4vvq/ every-insult-the-left-uses-to-troll-conservativesexplained

Chagas, V., Freire, F., Rios, D., \& Magalhães, D. (2019). Political memes and the politics of memes: A methodological proposal for content analysis of online political memes. First Monday, 24(2).

Coker, C. (2008). War, memes and memeplexes. International Affairs, 84(5), 903-914.

Davey, J., Saltman, E. M., \& Birdwell, J. (2018). The main- streaming of far-right extremism online and how to counter it. In L. Herman \& J. Muldoon (Eds.). Trumping the mainstream: The conquest of democratic politics by the populist radical right (pp. 23-53). London: Routledge.

Dawkins, R. (1976). The selfish gene. Oxford: Oxford University Press.

Dematagoda, U. (2017). Revenge of the nerds: Recidivist masculinity, identity politics and the online 'culture wars.' Journal of Extreme Anthropology, 1(3), 139-148.

Denisova, A. (2019). Internet memes and society: Social, cultural, and political contexts. London: Routledge.

Fang, K., \& Repnikova, M. (2018). Demystifying "little pink": The creation and evolution of a gendered label for nationalistic activists in China. New Media \& Society, 20(6), 2162-2185.

Flisfeder, M. (2018). "Trump": What does the name signify? Or, Protofascism and the alt-right: Three contradictions of the present conjuncture. Public Culture, 14(1), 1-19.

Flores-Saviaga, C. I., Keegan, B. C., \& Savage, S. (2018). Mobilizing the trump train: Understanding collective action in a political trolling community. In K. Starbird \& I. Weber (Eds.), Twelfth International AAAI Conference on Web and Social Media (pp. 82-91). Palo Alto, CA: AAAI Press.

Frier, S., \& Dennis, S. (2018, December 17). Instagram was bigger Russian election tool than Facebook, senate report says. Bloomberg. Retrieved from https:// www.bloomberg.com/news/articles/2018-12-17/ instagram-was-bigger-russian-election-tool-thanfacebook-report

Gal, N. (2018). Internet memes. In Barney Warf (Ed.). The SAGE encyclopedia of the Internet (pp. 529-530). Thousand Oaks, CA: SAGE.

Gallagher, T. (2019). Trump TV: The Trump campaign's real news update as competitor to cable news. Visual Communication Quarterly, 26(1), 32-43.

Häkkinen, A., \& Leppänen, S. (2014). YouTube meme warriors: Mashup videos as political critique. Tilburg Papers Culture Studies, 86. Retrieved from http://citeseerx.ist.psu.edu/viewdoc/download? doi=10.1.1.641.7774\&rep=rep1\&type $=p d f$

Hannan, J. (2018). Trolling ourselves to death? Social media and post-truth politics. European Journal of Communication, 33(2), 214-226.

Harmer, E., \& Lumsden, K. (2019). Online culture wars: The rise of the alt-right, Trumpism and white masculinities. In K. Lumsden \& E. Harmer (Eds.), Online othering: Exploring digital violence and discrimination on the web (pp. 35-115). Berlin: Springer.

Heikkilä, N. (2017). Online antagonism of the alt-right in the 2016 election. European journal of American studies, 12(12/2). https://doi.org/10.4000/ejas. 12140

Highfield, T., \& Leaver, T. (2015). A methodology for mapping Instagram hashtags. First Monday, 20(1), 1-11. 
Highfield, T., \& Leaver, T. (2016). Instagrammatics and digital methods: Studying visual social media, from selfies and GIFs to memes and emoji. Communication Research and Practice, 2(1), 47-62.

Hine, G. E., Onaolapo, J., De Cristofaro, E., Kourtellis, N., Leontiadis, I., Samaras, R., . . . Blackburn, J. (2017). Kek, cucks, and god emperor trump: A measurement study of 4chan's politically incorrect forum and its effects on the web. In D. Ruths (Ed.), Eleventh International AAAl Conference on Web and Social Media (pp. 92-101). Palo Alto, CA: AAAI Press.

Howley, K. (2016). 'I have a drone': Internet memes and the politics of culture. Interactions: Studies in Communication \& Culture, 7(2), 155-175.

Jenkins, H. (2006). Convergence culture. New York, NY: New York University Press.

Jhaveri, I. (2019). When is a frog not a frog? Building a new digital tool to track political symbols. Columbia Journalism Review. Retrieved from https://www.cjr. org/tow_center/political-symbols-tow-center.php

Know Your Meme. (2018). Clown Pepe/Honk Honk/Clown World. Know Your Meme. Retrieved from https://knowyourmeme.com/memes/clownpepe-honk-honk-clown-world

Lasn, K. (2012). Meme wars: The creative destruction of neoclassical economics. London: Penguin.

Lazer, D. M., Baum, M. A., Benkler, Y., Berinsky, A. J., Greenhill, K. M., Menczer, F., . . . Schudson, M. (2018). The science of fake news. Science, 359(6380), 1094-1096.

Leskovec, J., Backstrom, L., \& Kleinberg, J. (2009). Memetracking and the dynamics of the news cycle. Paper presented at ACM SIGKDD International Conference on Knowledge Discovery and Data Mining, Paris, France.

Lonkila, M. (2017). Social network sites and political governance in Russia. In V. Gel'man (Ed.), Authoritarian modernization in Russia: Ideas, institutions, and policies (pp. 113-127). London: Routledge.

Martínez-Rolán, X., \& Piñeiro-Otero, T. (2016). The use of memes in the discourse of political parties on Twitter: Analysing the 2015 state of the nation debate. Communication \& Society, 29(1), 145-159.

Meme. (2020). In Oxford English dictionary. Retrieved from https://www.lexico.com/definition/meme

Merrin, W. (2019). President troll: Trump, 4Chan and memetic warfare. In C. Happer, A. Hoskins, \& W. Merrin (Eds.), Trump's media war (pp. 201-226). London: Palgrave Macmillan.

Miltner, K. (2014). "There's no place for lulz on LOLCats": The role of genre, gender and group identity in the interpretation and enjoyment of an Internet meme. First Monday, 19(8). Retrieved from http:// firstmonday.org/ojs/index.php/fm/article/view/ 5391/4103

Nissenbaum, A., \& Shifman, L. (2017). Internet memes as contested cultural capital: The case of 4chan's/b/board. New Media \& Society, 19(4),
483-501.

Pauca, V. P., Shahnaz, F., Berry, M. W., \& Plemmons, R. J. (2004). Text mining using non-negative matrix factorizations. In M. Berry, C. Kamath, U. Dayal, \& D. Skillicorn (Eds.), Proceedings of the 2004 SIAM International Conference on Data Mining (pp. 452-456). Philadelphia, PA: Society for Industrial and Applied Mathematics.

Revesz, R. (2016, September 13). Hillary Clinton attacks Donald Trump for posting Pepe the Frog meme. The Independent. Retrieved from https://www. independent.co.uk/news/world/americas/donaldtrump-hillary-clinton-pepe-frog-instagram-breitbartwhite-supremacist-alex-jones-milo-a7240581.html

Roose, K. (2017, July 5). How a CNN investigation set off an Internet meme war. The New York Times. Retrieved from https://www.nytimes.com/2017/07/ 05/business/how-a-cnn-investigation-set-off-aninternet-meme-war.html

Rose, G. (2016). Visual methodologies: An introduction to researching with visual materials. California, CA: SAGE.

Schreckinger, B. (2017, March/April). World war meme. Politico. Retrieved from http://politi.co/2F5wv98

Seiffert-Brockmann, J., Diehl, T., \& Dobusch, L. (2018). Memes as games: The evolution of a digital discourse online. New Media \& Society, 20(8), 2862-2879.

Shifman, L. (2012). An anatomy of a YouTube meme. New Media \& Society, 14(2), 187-203.

Shifman, L. (2014). Memes in digital culture. Cambridge, MA: MIT Press.

Tay, G. (2014). Binders full of LOLitics: Political humour, internet memes, and play in the 2012 US Presidential Election (and beyond). European Journal of Humour Research, 2(4), 46-73. https://doi.org/ 10.7592/EJHR2014.2.4.tay

Townsend, L., \& Wallace, C. (n.d.). Social media research: A guide to ethics. Aberdeen: The University of Aberdeen. Retrieved from https://www.gla.ac.uk/ media/media_487729_en.pdf

Trump, D. [realDonaldTrump]. (2018, October 21). Facebook has just stated that they are setting up a system to "purge" themselves of Fake News. Does that mean CNN will finally be put out of business? [Tweet]. Retrieved from https://twitter.com/ realDonaldTrump/status/1054142516881248258

Vaca, C. K., Mantrach, A., Jaimes, A., \& Saerens, M. (2014, April). A time-based collective factorization for topic discovery and monitoring in news. In P. Ipeirotis (Eds.), Proceedings of the 23rd International Conference on World Wide Web (pp. 527-538). New York, NY: ACM.

Vosoughi, S., Roy, D., \& Aral, S. (2018). The spread of true and false news online. Science, 359(6380), 1146-1151.

Wiggins, B. E., \& Bowers, G. B. (2015). Memes as genre: A structurational analysis of the memescape. New Media \& Society, 17(11), 1886-1906. 
Williams, Z. (2016, June 12). (((Echoes))): Beating the far-right, two triple-brackets at a time. The Guardian. Retrieved from https://www.theguardian.com/ technology/shortcuts/2016/jun/12/echoes-beatingthe-far-right-two-triple-brackets-at-a-time

Wimmer, R., \& Dominick, J. (2013). Mass media research: An introduction. Boston, MA: Wadsworth, Cengage Learning.
Woolley, S. C., \& Guilbeault, D. R. (2017). Computational propaganda in the United States of America: Manufacturing consensus online (Computational Propaganda Research Project Working Paper No.2017.5). Oxford: University of Oxford.

Yang, G. (2014). Political contestation in Chinese digital spaces: Deepening the critical inquiry. China Information, 28(2), 135-144.

\section{About the Author}

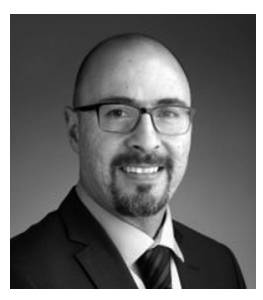

Ahmed Al-Rawi is an Assistant Professor of News, Social Media, and Public Communication at the School of Communication at Simon Fraser University, Canada. He is the Director of the Disinformation Project that empirically examines fake news discourses in Canada on social media and news media. Al-Rawi authored five books and over 90 peer reviewed book chapters and articles published in a variety of journals like Information, Communication \& Society, Online Information Review, Social Science Computer Review, and Telematics \& Informatics. 